Case Report

\title{
Continued Root Formation after Delayed Replantation of an Avulsed Immature Permanent Tooth
}

\author{
Nima Moradi Majd, ${ }^{1}$ Heidar Zohrehei, ${ }^{2}$ Alireza Darvish, ${ }^{1}$ \\ Hamed Homayouni, ${ }^{1}$ and Mamak Adel ${ }^{1}$ \\ ${ }^{1}$ Department of Endodontics, Dental School, Qazvin University of Medical Sciences, Qazvin 34157-59811, Iran \\ ${ }^{2}$ Dental Research Center, Shahid Beheshti University of Medical Sciences, Evin, Tehran 1983963113, Iran
}

Correspondence should be addressed to Heidar Zohrehei; h_zohrehei@yahoo.com

Received 21 February 2014; Revised 12 April 2014; Accepted 28 April 2014; Published 8 May 2014

Academic Editor: Malka Ashkenazi

Copyright (C) 2014 Nima Moradi Majd et al. This is an open access article distributed under the Creative Commons Attribution License, which permits unrestricted use, distribution, and reproduction in any medium, provided the original work is properly cited.

Introduction. Tooth avulsion in the young permanent dentition is a frequent finding, and its prognosis depends on the treatment of the avulsed tooth before replantation, the extra-alveolar time, the storage medium, and the patient's general health. The present report describes management of an immature avulsed lower central incisor 90 minutes after the accident. Methods. A right lower central incisor of a 7-year-old girl was avulsed, and it was soaked in a glass of milk. 90 minutes after avulsion, replantation was performed, and the tooth was splinted; but after two weeks the replanted tooth's pulp was necrotic. Thus, endodontic treatment was performed and root canal was filled using a calcium hydroxide and iodoform paste (Metapex). Three months later, the intracanal medication was washed out and the canal was sealed using an apical plug of calcium enriched mixture (CEM) cement. Results. 20 months after replantation the tooth was completely asymptomatic, with physiologic mobility. Also, continued root formation including an apical segment beyond the artificial apical plug was observed. Conclusion. Creation of an appropriate apical barrier following the disinfection of root canal system promoted continued root-end growth in a replanted immature permanent tooth.

\section{Introduction}

Traumatic injury to the young permanent dentition is a frequent finding [1]. Avulsion of permanent teeth usually occurs in children aged 8-10 years, due in part to short and incomplete roots and resilient periodontium and bone [2]. Although multiple avulsions and involvement of alveolar bone have been reported occasionally, single tooth avulsion is most common [1].

Prognosis depends on the treatment of the avulsed tooth before replantation, the extra-alveolar time, the storage medium, and the patient's general health $[3,4]$.

The following complications can occur after the teeth avulsion: pulp necrosis, damage to attachment tissue, and small localized destruction of cementum [5].

According to the guidelines which have been published by the International Association of Dental Traumatology (IADT) [6], treatment of an avulsed tooth depends upon the extra-alveolar dry time. In cases of open apices or partially developed roots with extraoral dry time less than sixty minutes, the avulsed teeth should be replanted immediately to allow revascularization [7].

Complete root development after pulp revascularization of the replanted immature permanent teeth has been reported several times [8-10], but continued root formation after root canal treatment of a replanted immature tooth has seldom been documented [11].

The present report describes management of an immature avulsed lower central incisor 90 minutes after the accident.

\section{Case Report}

A healthy 7-year-old girl was referred to the Endodontic Department of Qazvin School of Dentistry. According to her mother, the girl's right lower central incisor was avulsed 
ninety minutes earlier, while she was playing. The tooth had been soaked in a glass of milk.

Intraoral examination revealed neither soft tissue laceration nor other teeth crown fracture. Periapical radiographic investigation did not show any evidence of associated hard tissue injury (Figure 1). Also, the avulsed tooth was examined, and it was found that it has intact structure with wide apical foramina.

The avulsed tooth was soaked in doxycycline $(1 \mathrm{mg} / 20 \mathrm{~mL})$ (Hakim Pharmaceutical Co., Tehran, Iran) for five minutes. At the same time, the socket was carefully debrided with physiologic saline solution. After that, under local anesthesia, the tooth was gently replanted, and then it was splinted using orthodontic wire (Figure 2). The patient was prescribed a chlorhexidine gluconate mouth rinse and 3 $\times 250 \mathrm{mg}$ amoxicillin daily for a week.

After two weeks, another periapical radiograph was taken and it was found that periapical radiolucency around the replanted tooth has considerably increased (Figure 3). Therefore, we decided to perform apexification. Thus, before removing splint, under local anesthesia, access cavity was prepared and canal was instrumented carefully using manual stainless steel files (Dentsply Maillefer, Switzerland) and irrigated with ten $\mathrm{mL}$ of sodium hypochlorite $2.5 \%$; then, the root canal space was dried with sterile paper points (ARIADENT, Tehran, Iran) and filled using a calcium hydroxide and iodoform paste (Metapex) (META BIOMED Co. Ltd., South Korea).

In order to place the Metapex, the syringe was inserted into the canal, and paste was pressed down into the pulp space. When the paste flowed back from the root canal into the access cavity, the syringe was slowly withdrawn. Then, tooth was restored temporarily.

After taking a periapical radiograph, it was found that, due to open apex, a part of Metapex was extruded from root canal space (Figure 4).

Patient was followed up regularly at 1 and 3 months (Figures 5 and 6). Ninety days after the replantation, a noticeable reduction of periapical radiolucency was observed. Thus, in order to reduce the risk of tooth fracture, we decided to fill the canal using an apical plug of calcium enriched mixture (CEM) cement (BioniqueDent, Iran). Therefore, the root canal was washed out with sodium hypochlorite $2.5 \%$, and the CEM cement was placed into the apical $4 \mathrm{~mm}$ of the canal. Tooth was obturated using vertical compaction technique with gutta-percha (Gapadent Co., Ltd., Korea) and AH26 sealer (DeTrey, Dentsply, Konstanz, Germany) and then access cavity was restored with composite restoration.

\section{Clinicoradiographical Follow Up}

Tooth mobility and sensitivity to percussion were examined every three months. The percussion tone was evaluated and compared with the adjacent teeth. At twelve-month followup radiograph, continued root formation was observed (Figure 7), and at 20 months after replantation the tooth was completely asymptomatic, with physiologic mobility. Also, at that time, continued root formation was very noticeable (Figure 8).

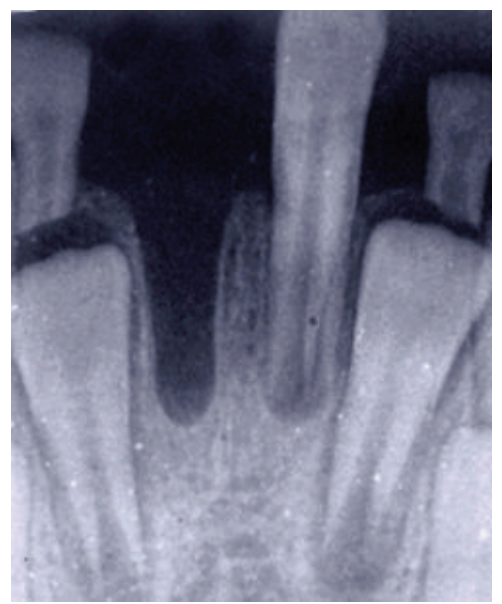

FIGURE 1: Preoperative radiograph showing the intact socket of right lower central incisor.

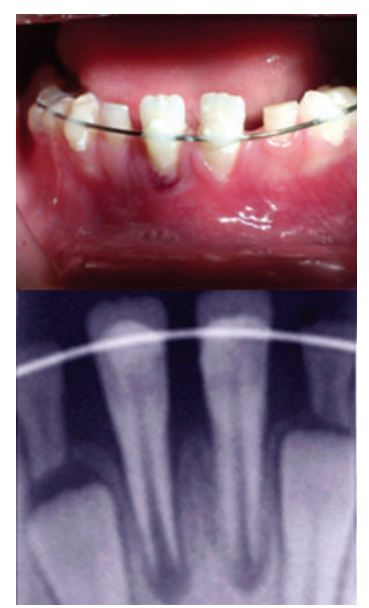

FIgURE 2: The right lower central incisor was splinted using orthodontic wire.

\section{Discussion}

The most important factor that impacts on treatment's outcome of the avulsed teeth is the extraoral dry time [7]. Although immediate replantation is the best available treatment for an avulsed tooth, for a variety of reasons this may not happen [7].

This case report describes a relatively severe, rare traumatic injury to an immature right lower central incisor. According to current literature $[3,12]$, replanting immature teeth is irrational when the extraoral dry time is more than 60 minutes. They stated that, in such cases, thin dentinal walls of immature teeth, wide dentinal tubules, and the high basal metabolic rate in children lead to an unsuccessful replantation. Although, in our case, the right lower central incisor was replanted after a relatively long extraoral period of time (90 min), the tooth had been placed in a glass of milk. 


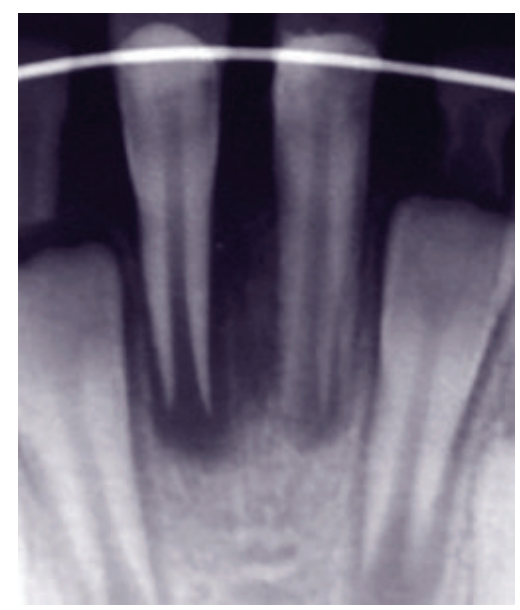

FIGURE 3: Two weeks after replantation, periapical radiolucency around the replanted tooth has increased considerably.

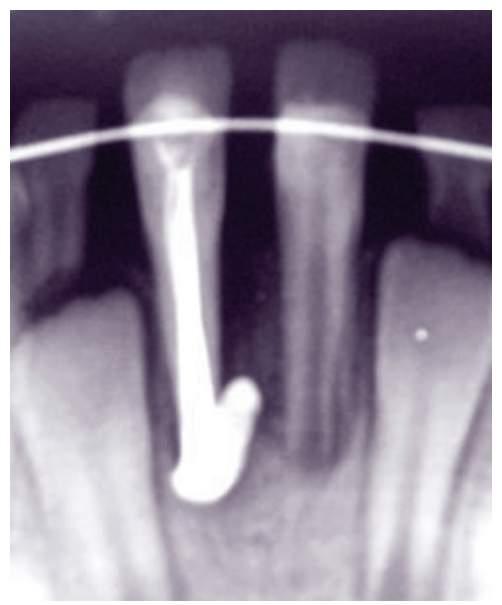

FIgURE 4: Root canal was filled using a calcium hydroxide and iodoform paste (Metapex).

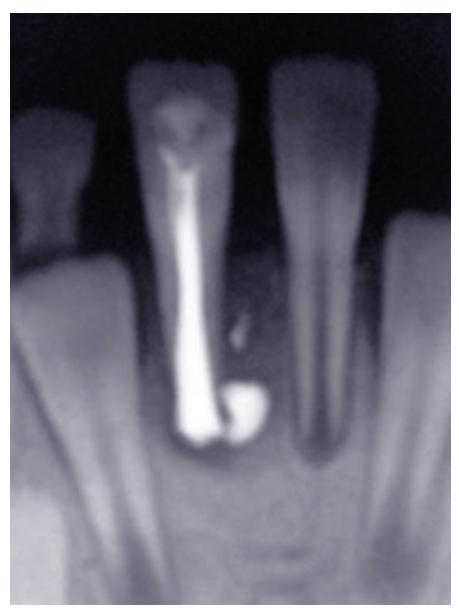

FIGURE 5: One month follow-up radiograph.

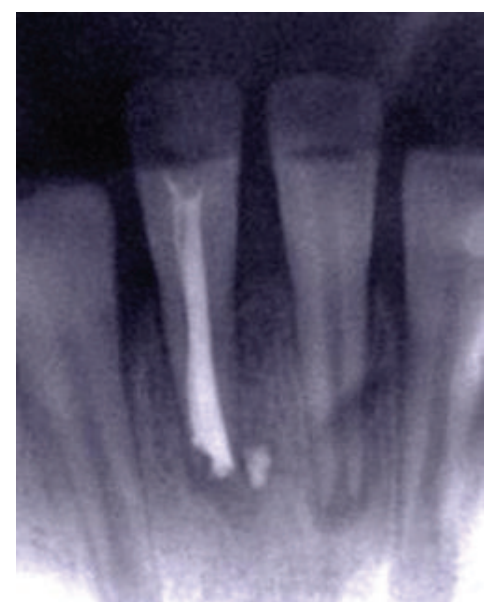

FIGURE 6: Three-month follow-up radiograph.

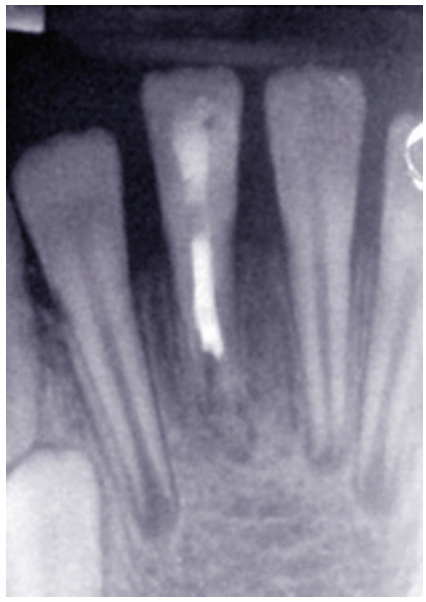

FIGURE 7: Twelve-month follow-up radiograph; continued root formation is detectable.

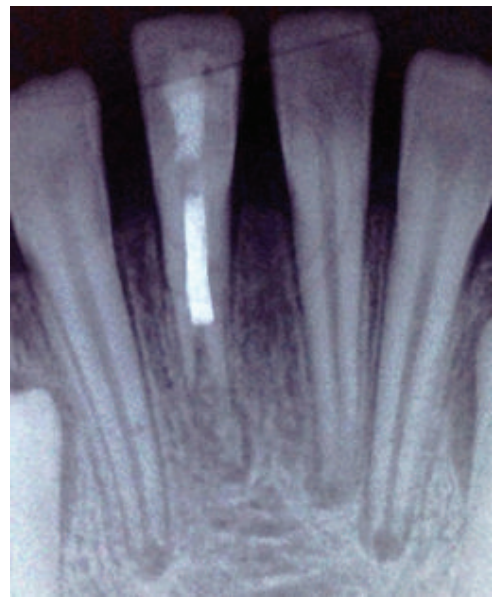

FIGURE 8: Twenty-month follow-up radiograph; continued root formation is very noticeable. 
Before replantation, we soaked the tooth in doxycycline for 5 minutes, because it has been shown that it enhances significantly the pulp revascularization in replanted immature teeth $[13,14]$.

The prerequisite for healing of an avulsed tooth is absence of infection [7]. Therefore, when increasing periapical radiolucency around the replanted tooth was observed, endodontic treatment to remove infected pulp tissue and stop resorption process was performed.

It has been suggested that placement of an intracanal medicament for a period ranging between 2 weeks and 6 months during root canal therapy of the avulsed teeth could have beneficial effect on the treatment's outcome [7]. In the previous studies several medications such as calcium hydroxide [15], endodontic medication based on steroids and antibiotics (Ledermix paste) [16], andthe mixture of calcium hydroxide and iodoform $[17,18]$ have been recommended.

Premixed calcium hydroxide paste containing iodoform resorbs from the apical tissues in a short period of time [19]; it is also apparently harmless to permanent tooth germs, does not set to a hard mass, and is easily inserted and removed [19]. Furthermore, it has been demonstrated that placement of calcium hydroxide and iodoform paste (Metapex) for treatment of an avulsed permanent tooth led to continued root-end growth and successful apexification [18].

Therefore, we placed calcium hydroxide and iodoform paste (Metapex) as an intracanal medicament for a relatively long period of time.

Three months after placement of the intracanal medication, periapical radiolucency around the replanted tooth was noticeably reduced. At that time, there were two treatment choices available: (1) long-term placement of calcium hydroxide to create a physiologic hard tissue barrier [20] and (2) creation of a hard tissue barrier with the endodontic biomaterials as the apical plugs [21, 22].

Although the formation of a physiologic hard tissue barrier is quite predictable, it takes anywhere from 3 to 18 months [20], andit has also been shown that long-term calcium hydroxide as a root canal dressing may increase risk of root fracture [23]. Thus, the second option was chosen.

In order to create the apical barrier, CEM cement was used. CEM cement is a biocompatible biomaterial [24] which has been utilized for the apexification and apexogenesis treatments in several studies $[25,26]$. It is demonstrated that it has an acceptable sealing ability when it is used to seal the root-end cavities [27] and furcal perforations [28]. Also, it has been shown that, in comparison to mineral trioxide aggregate (MTA), CEM cement's apical plug has superior sealing ability [29].

Torabinejad et al. [30] hypothesized that cementogenic properties of an artificial apical plug might be because of several features such as biocompatibility, alkalinity, and sealing ability. As mentioned before biocompatibility of CEM cement has been demonstrated previously [31]. Also, CEM cement is an alkaline biomaterial $(\mathrm{pH}>10.5)$ [32] with an acceptable sealing ability $[27,33]$.

One year after replantation of the tooth number 25 , continued root formation including an apical segment beyond the artificial apical barrier was observed, and 8 months later the continued root growth was more noticeable. Considering the fact that continued root formation after replantation and root canal treatment in an avulsed tooth has been reported previously [11], it seems that, even in a replanted tooth, a completely disinfected root canal with a tight coronal seal can provide an appropriate condition for activation of hard tissue formation process in periapical tissues. To explain this phenomenon, some possible mechanisms could be considered.

The first mechanism is the role of root organization of Hertwig's sheath; it is possible that this sheath survived and retained its ability to organize root formation when the inflammatory process was eliminated $[34,35]$.

The second mechanism is the mesenchymal stem cells in the apical papilla of permanent immature teeth; these cells are the source of odontoblasts and can develop root dentin [36]. It has been demonstrated that even if infection of root canal space reaches the periradicular tissues, these stem cells may survive and contribute to tissue regeneration [36].

In the present case, 20 months after replantation, the right lower central incisor was completely asymptomatic and functional; although the last periapical radiograph might make the observer suspicious of replacement resorption, the percussion tone was the same as that of the healthy adjacent tooth, and it was mobile within normal limits.

It is clear that long-term follow up for this tooth is favorable. Also, further studies are needed to evaluate the accurate development mechanism in cases that are like this kind of condition.

\section{Conclusion}

Creation of an appropriate apical barrier following the disinfection of root canal system promoted continued root-end growth in a replanted immature permanent tooth.

\section{Conflict of Interests}

The authors declare that there is no conflict of interests regarding the publication of this paper.

\section{References}

[1] H. Karayilmaz, Z. Kirzioglu, and O. Erken Gungor, "Aetiology, treatment patterns and long-term outcomes of tooth avulsion in children and adolescents," Pakistan Journal of Medical Sciences, vol. 29, no. 2, pp. 464-468, 2013.

[2] N. K. Sharma and M. S. Duggal, "Replantation in general dental practice," British Dental Journal, vol. 176, no. 4, pp. 147-151, 1994.

[3] N. Cohenca, S. Karni, D. Eidlitz, E. Nuni, and J. Moshonov, "New treatment protocols for avulsed teeth," Refuat Hapeh Vehashinayim, vol. 21, no. 2, pp. 48-53, 2004.

[4] M. T. Flores, L. Andersson, J. O. Andreasen et al., "Guidelines for the management of traumatic dental injuries. II. Avulsion of permanent teeth," Endodontic Topics, vol. 14, pp. 110-118, 2006.

[5] M. Trope, "Clinical management of the avulsed tooth," Dental Clinics of North America, vol. 39, no. 1, pp. 93-112, 1995.

[6] L. Andersson, J. O. Andreasen, P. Day et al., "International Association of Dental Traumatology guidelines for the management 
of traumatic dental injuries: 2. Avulsion of permanent teeth," Dental Traumatology, vol. 28, no. 2, pp. 88-96, 2012.

[7] D. Ram and O. N. Cohenca, "Therapeutic protocols for avulsed permanent teeth: review and clinical update," Pediatric Dentistry, vol. 26, no. 3, pp. 251-255, 2004.

[8] E. Davidovich, M. Moskovitz, and J. Moshonov, "Replantation of an immature permanent central incisor following preeruptive traumatic avulsion," Dental Traumatology, vol. 24, no. 5, pp. e47-e52, 2008.

[9] A. P. Goldbeck and K. L. Haney, "Replantation of an avulsed permanent maxillary incisor with an immature apex: report of a case," Dental Traumatology, vol. 24, no. 1, pp. 120-123, 2008.

[10] S. Mesaros and M. Trope, "Revascularization of traumatized teeth assessed by laser Doppler flowmetry: case report," Endodontics \& Dental Traumatology, vol. 13, pp. 24-30, 1997.

[11] S. Wang, M. Chung, W. Su, J. Cheng, and Y. Shieh, "Continued root formation after replantation and root canal treatment in an avulsed immature permanent tooth: a case report," Dental Traumatology, vol. 26, no. 2, pp. 182-185, 2010.

[12] B. Malmgren and O. Malmgren, "Rate of infraposition of reimplanted ankylosed incisors related to age and growth in children and adolescents," Dental Traumatology, vol. 18, no. 1, pp. 28-36, 2002.

[13] M. Cvek, P. Cleaton-Jones, J. Austin, J. Lownie, M. Kling, and P. Fatti, "Effect of topical application of doxycycline on pulp revascularization and periodontal healing in reimplanted monkey incisors," Endodontics \& Dental Traumatology, vol. 6, no. 4, pp. 170-176, 1990.

[14] K. Yanpiset and M. Trope, "Pulp revascularization of replanted immature dog teeth after different treatment methods," Dental Traumatology, vol. 16, no. 5, pp. 211-217, 2000.

[15] T. D. Larson, "Causes and treatment of root resorption," Northwest Dentistry, vol. 89, no. 3, pp. 45-47, 2010.

[16] E. C. Bryson, L. Levin, F. Banchs, P. V. Abbott, and M. Trope, "Effect of immediate intracanal placement of Ledermix Paste on healing of replanted dog teeth after extended dry times," Dental Traumatology, vol. 18, no. 6, pp. 316-321, 2002.

[17] Q. Weng, "Clinical study on the effect of Vitapex paste in apexification,” Hua Xi Kou Qiang Yi Xue Za Zhi, vol. 22, no. 3, pp. 214-215, 2004.

[18] N. Sridhar and S. Tandon, "Continued root-end growth and apexification using a calcium hydroxide and iodoform paste (Metapex): three case reports," Journal of Contemporary Dental Practice, vol. 11, no. 5, pp. 63-70, 2010.

[19] C. Nurko and F. Garcia-Godoy, "Evaluation of a calcium hydroxide/iodoform paste (Vitapex) in root canal therapy for primary teeth," Journal of Clinical Pediatric Dentistry, vol. 23, no. 4, pp. 289-294, 1999.

[20] E. C. Sheehy and G. J. Roberts, "Use of calcium hydroxide for apical barrier formation and healing in non-vital immature permanent teeth: a review," British Dental Journal, vol. 183, no. 7, pp. 241-246, 1997.

[21] S. Shabahang, "Treatment options: apexogenesis and apexification," Pediatric Dentistry, vol. 35, no. 2, pp. 125-128, 2013.

[22] M. Parirokh and M. Torabinejad, "Mineral trioxide aggregate: a comprehensive literature review, part III: clinical applications, drawbacks, and mechanism of action," Journal of Endodontics, vol. 36, no. 3, pp. 400-413, 2010.

[23] J. O. Andreasen, B. Farik, and E. C. Munksgaard, "Long-term calcium hydroxide as a root canal dressing may increase risk of root fracture," Dental Traumatology, vol. 18, no. 3, pp. 134-137, 2002.
[24] J. Ghoddusi, J. Tavakkol Afshari, Z. Donyavi, A. Brook, R. Disfani, and M. Esmaeelzadeh, "Cytotoxic effect of a new endodontic cement and mineral trioxide aggregate on L929 line culture," Iranian Endodontic Journal, vol. 3, pp. 17-23, 2008.

[25] A. Nosrat, S. Asgary, M. J. Eghbal, J. Ghoddusi, and S. BayatMovahed, "Calcium-enriched mixture cement as artificial apical barrier: a case series," Journal of Conservative Dentistry, vol. 14, no. 4, pp. 427-431, 2011.

[26] A. Nosrat and S. Asgary, "Apexogenesis of a symptomatic molar with calcium enriched mixture," International Endodontic Journal, vol. 43, no. 10, pp. 940-944, 2010.

[27] S. Asgary, M. J. Eghbal, M. Parirokh, and H. Torabzadeh, "Sealing ability of three commercial mineral trioxide aggregates and an experimental root-end filling material," Iranian Endodontic Journal, vol. 1, pp. 101-105, 2006.

[28] R. Haghgoo, S. Arfa, and S. Asgary, "Microleakage of CEM cement and proroot MTA as furcal perforation repair materials in primary teeth," Iranian Endodontic Journal, vol. 8, no. 4, pp. 187-190, 2013.

[29] M. Adel, M. M. Nima, S. Shivaie Kojoori, H. Norooz Oliaie, N. Naghavi, and S. Asgary, "Comparison of endodontic biomaterials as apical barriers in simulated open apices," ISRN Dentistry, vol. 2012, Article ID 359873, 5 pages, 2012.

[30] M. Torabinejad, T. Pitt Ford, D. Mckendry, H. Abedi, D. Miller, and S. Kariyawasam, "Histologic assessment of mineral trioxide aggregate as a root-end filling in monkeys," Journal of Endodontics, vol. 23, pp. 225-228, 1997.

[31] S. Asgary, M. J. Eghbal, and S. Ehsani, "Periradicular regeneration after endodontic surgery with calcium-enriched mixture cement in dogs," Journal of Endodontics, vol. 36, no. 5, pp. 837841, 2010.

[32] S. Asgary, S. Shahabi, T. Jafarzadeh, S. Amini, and S. Kheirieh, "The properties of a new endodontic material," Journal of Endodontics, vol. 34, no. 8, pp. 990-993, 2008.

[33] S. Asgary, M. J. Eghbal, and M. Parirokh, "Sealing ability of a novel endodontic cement as a root-end filling material," Journal of Biomedical Materials Research A, vol. 87, no. 3, pp. 706-709, 2008.

[34] M. Cvek, "Prognosis of luxated non-vital maxillary incisors treated with calcium hydroxide and filled with gutta-percha. A retrospective clinical study," Endodontics \& Dental Traumatology, vol. 8, no. 2, pp. 45-55, 1992.

[35] L. Safi and S. Ravanshad, "Continued root formation of a pulpless permanent incisor following root canal treatment: a case report," International Endodontic Journal, vol. 38, no. 7, pp. 489-493, 2005.

[36] G. T.-J. Huang, W. Sonoyama, Y. Liu, H. Liu, S. Wang, and S. Shi, "The hidden treasure in apical papilla: the potential role in pulp/dentin regeneration and bioroot engineering," Journal of Endodontics, vol. 34, no. 6, pp. 645-651, 2008. 


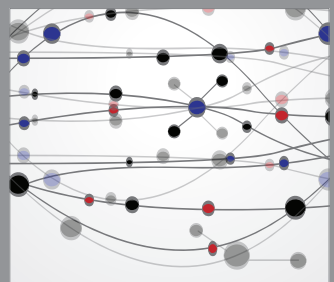

The Scientific World Journal
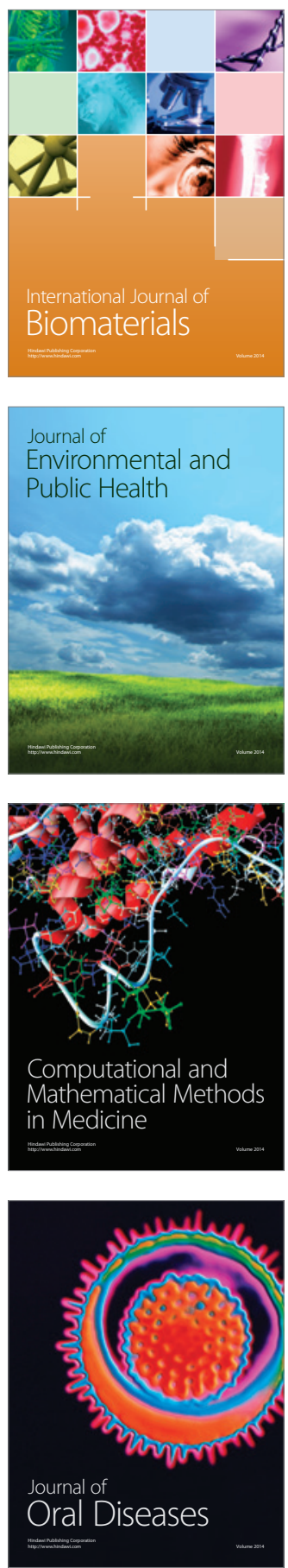
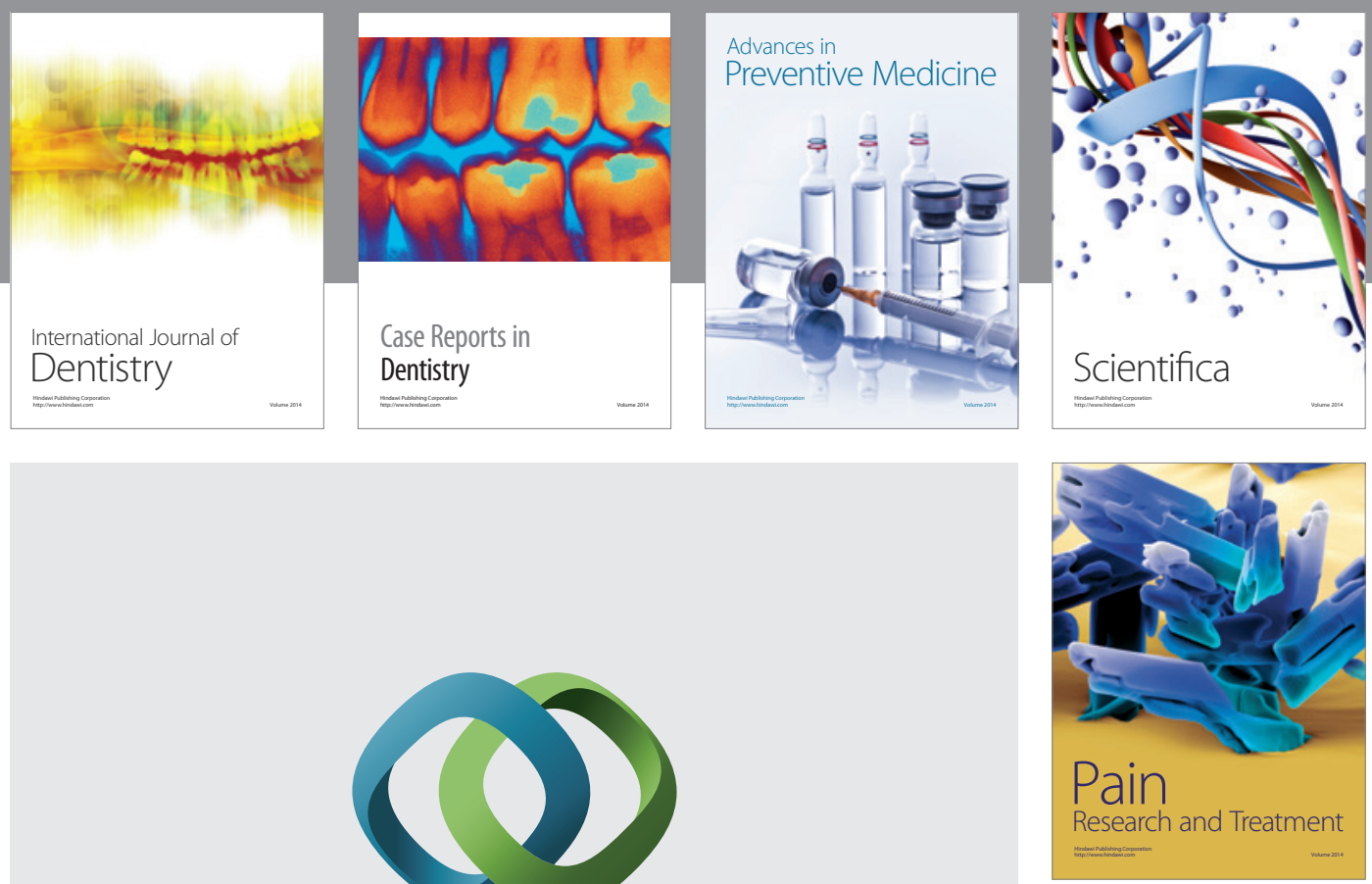

\section{Hindawi}

Submit your manuscripts at

http://www.hindawi.com
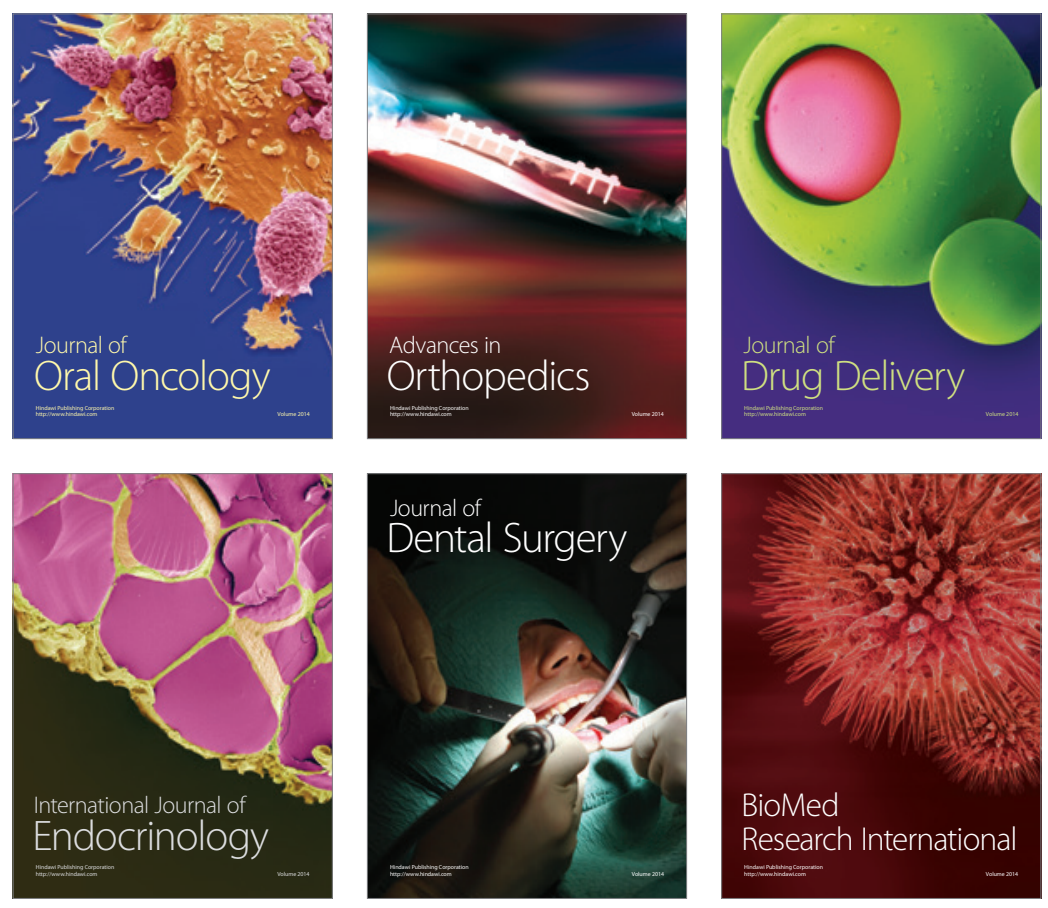

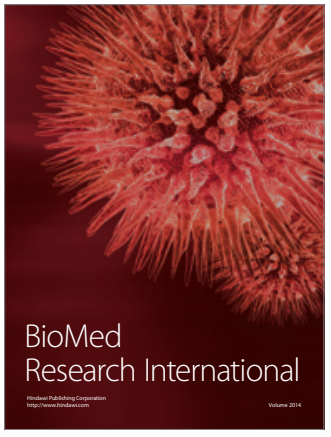

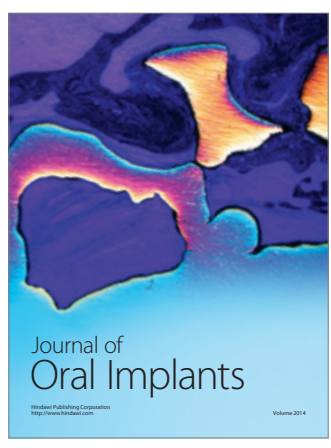
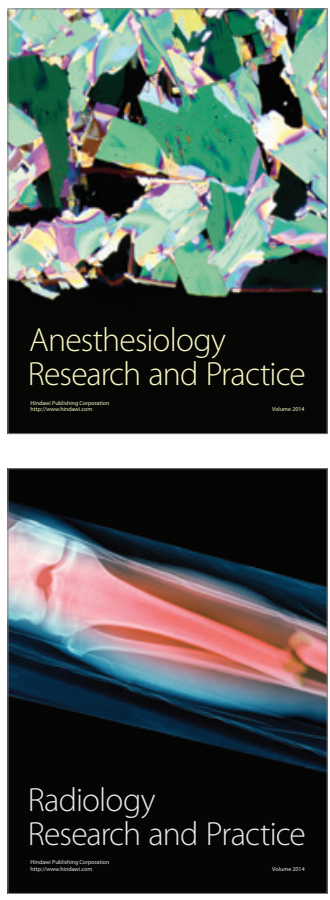